\title{
Selection of hydrologic modeling approaches for climate change assessment: A comparison of model scale and structures
}

\author{
Christopher G. Surfleet ，Desirèe Tullos , Heejun Chang Il-Won Jung
}

\begin{abstract}
S U M M A R Y
A wide variety of approaches to hydrologic (rainfall-runoff) modeling of river basins confounds our ability to select, develop, and interpret models, particularly in the evaluation of prediction uncertainty associated with climate change assessment. To inform the model selection process, we characterized and compared three structurally-distinct approaches and spatial scales of parameterization to modeling catchment hydrology: a large-scale approach (using the VIC model; $671,000 \mathrm{~km}^{2}$ area), a basin-scale approach (using the PRMS model; $29,700 \mathrm{~km}^{2}$ area), and a site-specific approach (the GSFLOW model; $4700 \mathrm{~km}^{2}$ area) forced by the same future climate estimates. For each approach, we present measures of fit to historic observations and predictions of future response, as well as estimates of model parameter uncertainty, when available. While the site-specific approach generally had the best fit to historic measurements, the performance of the model approaches varied. The site-specific approach generated the best fit at unregulated sites, the large scale approach performed best just downstream of flood control projects, and model performance varied at the farthest downstream sites where streamflow regulation is mitigated to some extent by unregulated tributaries and water diversions. These results illustrate how selection of a modeling approach and interpretation of climate change projections require (a) appropriate parameterization of the models for climate and hydrologic processes governing runoff generation in the area under study, (b) understanding and justifying the assumptions and limitations of the model and (c) estimates of uncertainty associated with the modeling approach.
\end{abstract}

\section{Introduction}

The prediction and interpretation of uncertain hydrologic responses to climate change is a major challenge for water resource managers (Brekke et al., 2009). An important effect of climate change is modification of local and regional water availability due to the climate system's interaction with the hydrologic cycle (e.g., Bates et al., 2008). Studies of climate change impacts on water resources in the Pacific Northwest (PNW) suggest changes will occur in the magnitude and timing of runoff (e.g., Chang and Jung, 2010; Elsner et al., 2010; Hamlet et al., 2010), the frequency and intensity of floods and droughts (e.g., Mote et al., 2003; Jung and Chang, 2011b), water temperature (Mantua et al., 2010; Chang and Lawler, 2011), nutrient and sediment loading (Praskievicz and Chang, 2011), and quantity of water available for human use (e.g., IPCC, 2007; Mote et al., 2003). These hydrologic changes, in turn, influence various aspects of water resource management, including municipal, irrigation, and industrial supply, hydropower generation, flood management, channel morphology, and aquatic habitat conservation. Some of these effects may not necessarily be negative, but need to be evaluated because of the socio-economic importance of water (Jiang et al., 2007).

Downscaled General Circulation Model (GCM) simulations are frequently used within a hydrologic model to predict how the changes to climate affect the water balance and water-related sectors using a variety of approaches and scales of analysis (e.g., Wilby et al., 2009). Large uncertainties are inherent in the predictions, depending on GCM structure and parameterization, downscaling procedure, greenhouse gas (GHG) emission scenario, hydrologic model used, and hydrologic model parameters (e.g., Maurer, 2007; Surfleet and Tullos, 2012; Xu et al., 2005; Im et al., 2010). The effect on hydrologic predictions using different GCMs, downscaling techniques, and GHG emission scenarios have received considerable attention (e.g., Maurer, 2007; Wood et al., 2004; Maurer and Duffy, 2005). However, fewer studies (e.g., Jiang et al., 2007; Najafi et al., 2011) have focused on differences in uncertainties of 
predictions associated with the various hydrologic modeling approaches, though uncertainty should be considered in the selection of hydrologic models.

The choice of the hydrologic model may depend on a number of selection criteria, including the character (e.g., relevant spatial and temporal scale, acceptable level of error and uncertainty for alternative screening vs. detailed design) (e.g., Clark et al., 2008) of the water resource management issue. In addition, the scale of variability in physical characteristics (e.g., land use, elevation, geology) that influences important hydrological processes (e.g., evapotranspiration, snow accumulation and melt, or groundwater recharge and discharge) can be a principle factor in selecting hydrologic models. Finally, aspects of the individual models may influence its appropriateness for an application, including ease of use that includes pre- and post-processing, hardware requirements, rigor and comprehensiveness of modeled processes, availability and quality of required data, adaptability of source code, model availability, and cost (Singh, 1995).

In the PNW, several different hydrologic modeling approaches have been conducted for climate impact assessment. When continental scale information for a variety of climate predictions were needed, the VIC macroscale ( $\sim 5-6 \mathrm{~km}$ grid cells) hydrologic model was applied (Nijssen et al., 1997; Hamlet and Lettenmaier, 1999; Elsner et al., 2010). If there is complexity and differences in hydrologic processes across the study area, but representation of smallscale spatial differences is not needed, then use of basin scale or regional parameters may be adequate (e.g., Chang and Jung, 2010; Jung and Chang, 2011a). If spatial heterogeneity in hydrogeology or subtle differences in hydrological processes over time have an important influence on runoff generation, then a site-specific modeling approach may be needed. For example, Tague et al. (2008) investigated the sensitivity of two Oregon Cascades basins, characterized by different geologic characteristics, under synthetic temperature warming scenarios using the Regional Hydro-Ecologic Simulation System (RHESSys). In urbanizing watersheds with multiple land use and water quality issues, Franczyk and Chang (2009) and Praskievicz and Chang (2011) used US EPA's physically-based model, BASINS-SWAT and BASINS-HSPF, respectively, in a site-specific approach.

With the goal of facilitating discussion on hydrologic model selection and development for use in water resources planning and design, we undertook the comparison of three modeling approaches using identical climate forcing data. We differentiate the modeling approaches by the spatial scale of the model application (Large Scale, Basin Scale, or Site-Specific) (Fig. 1) the model used, and the quantification of uncertainty within the modeling approach.

(a) Large scale (LS) deterministic approach by the Variable Infiltration Capacity (VIC) model (Liang et al., 1994) for the Columbia River basin considering GCM uncertainty.

(b) Basin scale parameters and uncertainty (BSPU) effort using a surface runoff model, Precipitation-Runoff Modeling System (PRMS) (Leavesley et al., 1983), with GCM uncertainty cascaded through a parameter uncertainty assessment using existing parameter set ranges.

(c) Site-specific modeling with uncertainty (SSMU) effort with a coupled groundwater and surface-water flow model (GSFLOW) (Markstrom et al., 2008; Harbaugh, 2005) with GCM uncertainty cascaded through a parameter uncertainty assessm.

The objectives of this analysis are: (a) to compare fit to historic hydrologic observations across three hydrologic modeling approaches with varying model structures and spatial scales of parameterization; (b) examine differences in predictions of future hydrology from the three modeling approaches, and; (c) investigate the physical processes responsible for differences in predictions to facilitate discussion on hydrologic model selection and parameterization. Model simulation results are summarized into four classes of hydrologic responses (extreme peak flows events, extreme low flow events, average monthly flow, and snowmelt) that are generally relevant to water resources management.

\section{Methods}

\subsection{Study areas, model comparison locations, and timeframes}

The Santiam River Basin (SRB, $4700 \mathrm{~km}^{2}$ ) is a tributary to the Willamette River Basin (WRB, 29,700 $\mathrm{km}^{2}$ ), which is itself a tributary to the Columbia River Basin (CRB, $671000 \mathrm{~km}^{2}$ ). Located on the western slopes of the Cascade Range in Oregon, USA (Fig. 1), the SRB is a valuable case study for model comparison because it is characterized by spatially heterogeneous hydrogeology, creating spatial variability in hydrologic response to changes in climate. The SRB varies from mountain terrain in high elevation alpine areas $(3199 \mathrm{~m})$ to low relief foothills to alluvial areas $(50 \mathrm{~m})$ that are hydrologically connected to the Willamette Valley. The land use classification within the basin is $80 \%$ forest, $15 \%$ agriculture, $2 \%$ urban, and $3 \%$ range (USGS, 2009). The soils in the SRB are classified (NRCS, 2007) as 80\% in Hydrologic Group B, with moderate rates of water transmission (infiltration and drainage) and $20 \%$ in Hydrologic Group A, with slow rates of water transmission. Precipitation varies from rain at the basin outlet to primarily snow at higher elevations, with a mix of rain and snow between the two (Fig. 1). Furthermore, two hydrologically-distinct seasons exist in the basin, a wet season (November through April) during which approximately $85 \%$ of precipitation occurs, and a dry season (May through October) during which $15 \%$ of precipitation occurs (NRCS, 2011).

The runoff from the SRB is regulated by four flood control projects, Detroit and Big Cliff dams on the North Fork Santiam River and Foster and Green Peter Dams on the South Fork Santiam River. The high elevation areas of the Santiam River are composed of High Cascades geology where runoff is influenced by discharge from a substantial, deep groundwater aquifer and springs (Tague et al., 2008; Chang and Jung, 2010; Surfleet and Tullos, 2012). The lower alluvial section of the basin include areas of considerable recharge for groundwater associated with the Willamette Valley aquifer, where low flow streamflow is strongly affected by aquifer conditions (Lee and Risley, 2002). The remainder of the basin has Western Cascade geology, characterized by moderate to low hydraulic conductivities coupled with shallow soils that result in a rapid runoff response with little groundwater storage (Tague et al., 2008).

Our hydrologic model predictions were compared at four locations within the SRB (Fig. 1) with one additional location for historical streamflow only; South Santiam at Cascadia. The four locations were selected due to the availability of output from the LS model, proximity to a river gauging station, and spatial differences in basin characteristics affecting hydrologic response (Table 1). We summarized results of the model simulations for three time periods: historic (1960-2006), 2040s (2030-2059), and 2080s (20702099). These time periods, representative of the middle and the end of the21st century, were used to allow comparison to already completed VIC modeling (Hamlet et al., 2010). The VIC modeling used a 30 year time period that bracketed 2040 and 2080 to represent these respective time periods. The historical values for the BSPU and SSMU approaches were calculated from USGS streamflow data. We used the published values from the VIC modeling 


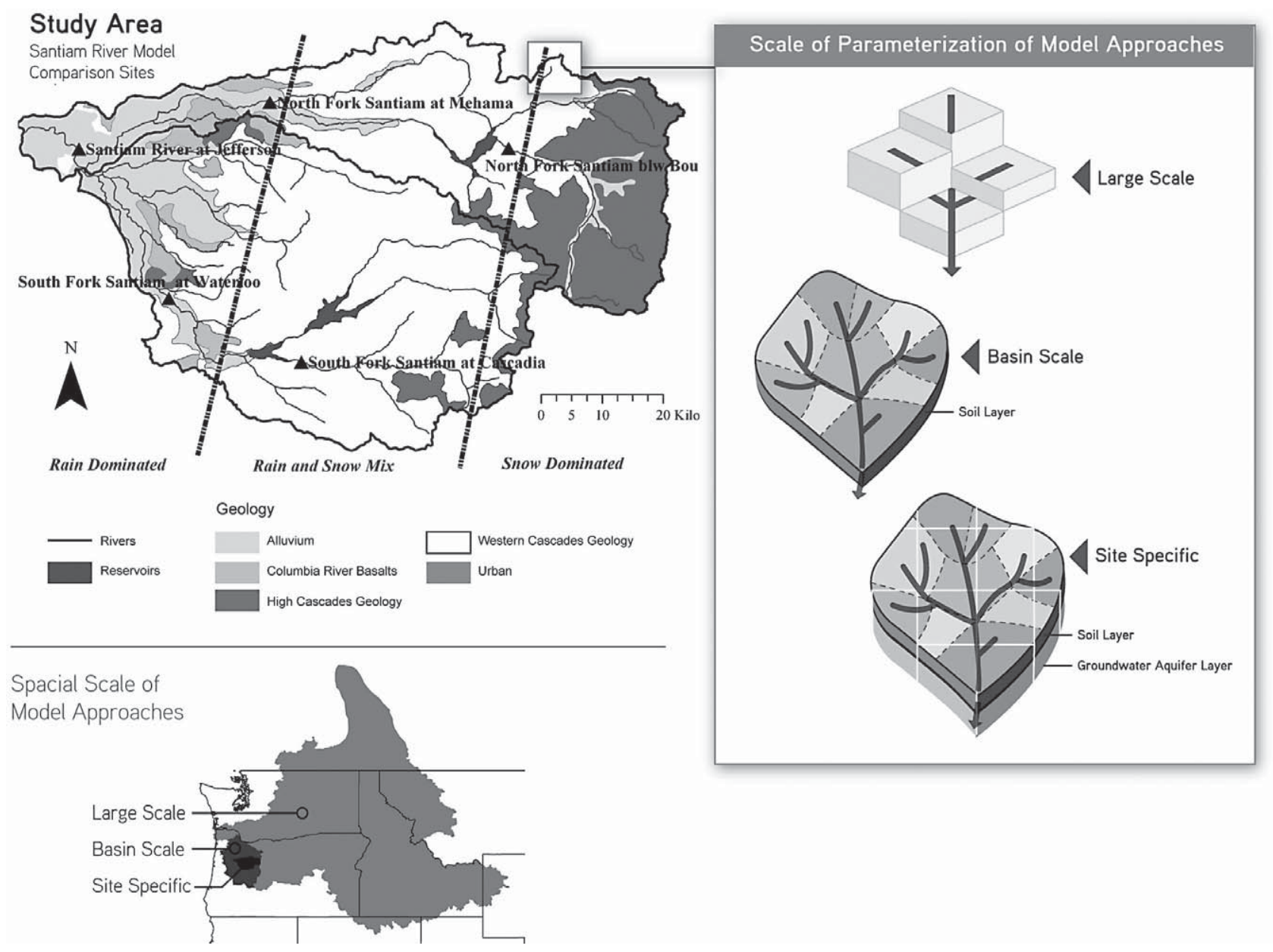

Fig. 1. Model approaches and Santiam River basin study area, Oregon, USA.

of the CRB (Hamlet et al., 2010) for the historical values in fitness comparisons made with the LS approach.

\subsection{Hydrologic models and approaches}

We evaluated three hydrologic (rainfall-runoff) modeling approaches for their ability to predict streamflow at four locations (Table 1) within the SRB with important distinctions in model structure and application (Table 2). Each of the models solve full water and energy balances that consider the effect of meteorological observations on potential evapotranspiration (from vegetation and land cover), water storage and routing (soil moisture, ground- water, snow, and stream channel), and the subsequent runoff (streamflow). The primary differences among the models are in the representation of hydrologic processes, as defined by the parameterization, calibration, validation, and spatial scale of modeling. The approach to the modeling differed as well with two of the approaches (BSPU and SSMU) considering parameter uncertainty and one approach that did not (LS). In all three approaches, the same $1 / 16^{\circ}$ resolution meteorological forcing data was used for historical and downscaled future predictions for the SRB (Table 3). We used eight GCM simulations with two emission scenarios (B1and A1B), which were statistically downscaled using the bias correction and spatial downscaling method (Wood et al., 2004).

Table 1

Characteristics affecting hydrologic response for the four locations of hydrologic model comparison in the Santiam River basin, Oregon.

\begin{tabular}{|c|c|c|c|c|c|c|}
\hline Location & $\begin{array}{l}\text { Area } \\
\left(\mathrm{km}^{2}\right)\end{array}$ & $\begin{array}{l}\text { Natural or } \\
\text { regulated }^{\mathrm{a}} \text { runoff }\end{array}$ & $\begin{array}{l}\text { Major } \\
\text { precipitation } \\
\text { type }\end{array}$ & $\begin{array}{l}\text { Mean } \\
\text { elev. }(\mathrm{m})\end{array}$ & Geology & $\begin{array}{l}\text { Groundwater influence on runoff } \\
\text { (high, moderate, low) }\end{array}$ \\
\hline $\begin{array}{l}\text { North Fork Santiam River } \\
\text { below Boulder Creek }\end{array}$ & 555 & Natural & Snow & 1255 & $\begin{array}{l}\text { 90\% High Cascade, } 5 \% \text { Western Cascade, } \\
5 \% \text { Alluvium }\end{array}$ & High \\
\hline $\begin{array}{l}\text { North Fork Santiam River at } \\
\text { Mehama }^{\mathrm{a}}\end{array}$ & 1700 & Regulated & Rain and snow & 1160 & $\begin{array}{l}30 \% \text { High Cascade, } 60 \% \text { Western } \\
\text { Cascade, } 10 \% \text { Alluvium }\end{array}$ & Moderate \\
\hline $\begin{array}{l}\text { South Fork Santiam River at } \\
\text { Waterloo }{ }^{\mathrm{a}}\end{array}$ & 1660 & Regulated & Rain and snow & 765 & $\begin{array}{l}\text { 90\% Western Cascade, 5\% Alluvium, 3\% } \\
\text { Basalt, 2\% High, Cascade }\end{array}$ & Low \\
\hline Santiam River at Jefferson ${ }^{a}$ & 4700 & $\begin{array}{l}60 \% \text { of Basin } \\
\text { regulated }\end{array}$ & Rain and snow & 740 & $\begin{array}{l}\text { 15\% High Cascade, } 60 \% \text { Western } \\
\text { Cascade, } 10 \% \text { Alluvium, 5\% Basalt }\end{array}$ & Moderate \\
\hline
\end{tabular}

\footnotetext{
a Regulated by flood control dams.
} 


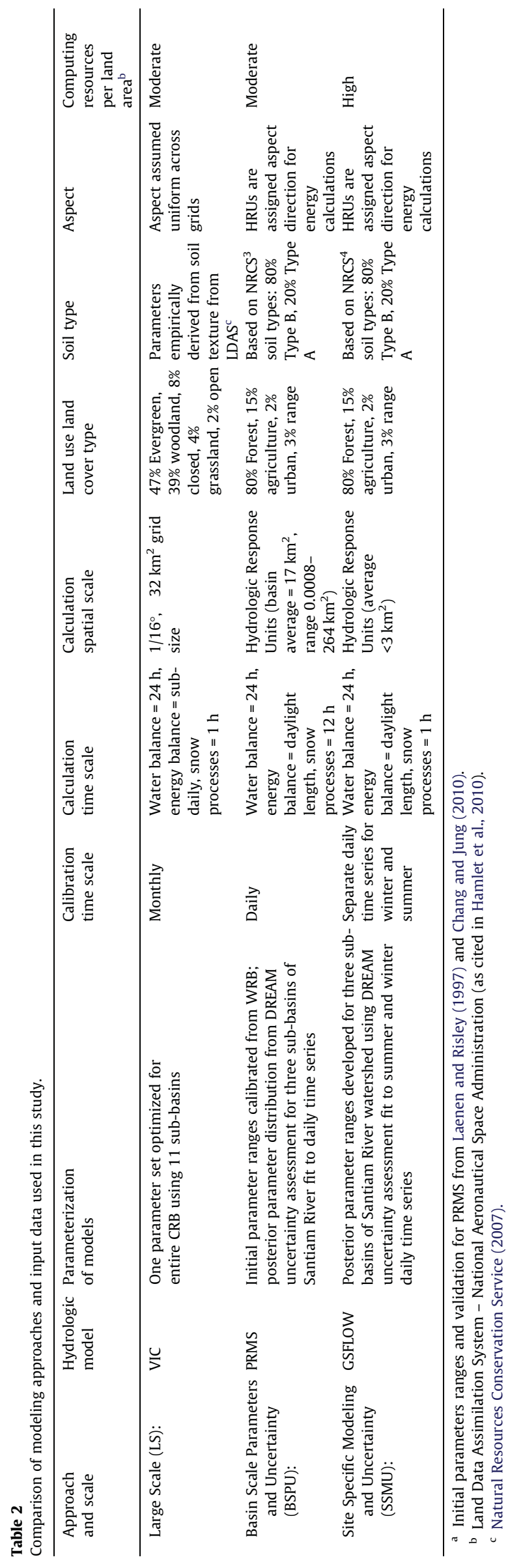

The average change of mean annual precipitation, mean daily maximum air temperature, and mean daily minimum air temperatures for the wet season (November through April) and dry season (May through October) from the downscaled GCM data used as input to the SRB modeling is presented (Table 4).

The LS modeling approach is represented by VIC modeling at grids of the same scale as the downscaled $1 / 16^{\circ} \mathrm{GCM}$ data (Fig. 1). This equates to approximately 15 grid cells per $500 \mathrm{~km}^{2}$ (Hamlet et al., 2010) ( $33 \mathrm{~km}^{2}$ per grid cell). The VIC model was calibrated for eleven large basins located east of the Cascade mountain divide within the CRB. One parameter set was developed from the VIC model calibration and used over the entire CRB. The parameter selections were deterministic; No analysis of equifinality and parameter uncertainty was undertaken. Calibration of the VIC model was based on adjusting infiltration, Ds, Ws, Dsmax, and soil depth using the MOCOM-UA method to fit monthly data; for greater detail on VIC model calibration and validation, please see Hamlet et al. (2010). Consideration of GCM uncertainty was addressed using different GCMs and several different statistical downscaling techniques (Hamlet et al., 2010). Vegetation and soil parameters used by VIC for the LS approach came from the LDAS (Land Data Assimilation System) (see Hamlet et al., 2010) assimilated from a scale of $1 \mathrm{~km}^{2}$. Leaf area index is the primary parameter used within VIC to model effects of vegetation on potential evapo-transpiration (PET). Soil parameters are used for calculation of variable infiltration capacity, which influence baseflow based on differences in soil moisture through time (Liang et al., 1994). Subgrid elevation bands are used to compensate for above-ground energy differences due to elevation. To calculate streamflow in larger basins, daily runoff and baseflow are used as input to a routing model (based on Lohmann et al. (1996)).

For the BSPU modeling approach, we used and reanalyzed results from a PRMS model that discretizes the landscape into Hydrologic Response Units (HRUs) at a finer scale (on average $<17 \mathrm{~km}^{2}$ ) than was used for the VIC model. The delineation of HRUs defined areas of similar vegetation type, land use, soil, aspect, and geology (Fig. 1) to serve as the spatial scale for model calculations. Parameters used to represent effects of vegetation types and land use were developed from GIS layers at $30 \mathrm{~m}$ resolution obtained from the United States Geological Survey (USGS, 2009). A $30 \mathrm{~m}$ digital elevation model was used to represent topographic changes of elevation and aspect (USGS, 2009). Soil attributes for model parameters were developed from soil data for the state of Oregon (NRCS, 1986). For fitting the PRMS and GSFLOW models to historical streamflow and snow data, we adjusted thirteen sensitive model parameters, as identified in previous PRMS models for the area (Chang and Jung, 2010; Laenen and Risley, 1997; Jung and Chang, 2011a,b) (Table 5). The published ranges of model parameters previously applied in the region were used as the $a$ priori parameter distributions for an uncertainty assessment (see Section 2.3).

The SSMU modeling approach used the GSFLOW model with calculations at the land surface performed at the same HRUs

Table 3

The eight Global Climate Models (GCM) used in the three modeling approaches.

\begin{tabular}{ll}
\hline GCM & References \\
\hline CCSM3 & Collins et al. (2006) \\
CNRM-CM3 & Terray et al. (1998) \\
ECHAM5/MPI-OM & Jungclaus et al. (2006) \\
ECHO-5 & Min et al. (2005) \\
IPSL-CM4 & Marti et al. (2005) \\
MIROC3.2 & K-1 Developers (2004) \\
PCM & Washington et al. (2000) \\
UKMO-HadCM3 & Gordon et al. (2000) \\
\hline
\end{tabular}




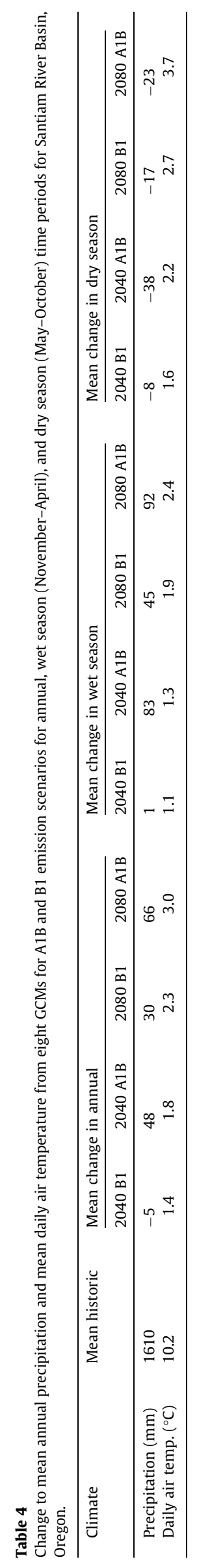

defined for the BPSU approach. The SSMU approach with GSFLOW adds the MODFLOW groundwater model to simulate sub-surface water. In GSFLOW infiltrated water passes from the smaller HRU scales, modeled by PRMS, into the deeper groundwater MODFLOW grids (a $4 \mathrm{~km}$ finite difference grid) with two to three- sub-surface layers for modeling of sub-surface water (Fig. 1) (for more details see Surfleet and Tullos, 2012). The groundwater model component of GSFLOW was calibrated by fitting model predictions to groundwater elevations from wells in the Willamette Valley and summer low flow as no groundwater elevation measurements were available for the mountainous portion of the SRB. A DREAM uncertainty assessment (see Section 2.3) was used for three sub-basins of the SRB for the SSMU approach to develop posterior distributions of parameter ranges for up to 13 model parameters (Table 5) in the surface water component of GSFLOW.

Both the BSPU and SSMU were parameterized by the same thirteen PRMS parameters (Table 5) (Chang and Jung, 2010; Laenen and Risley, 1997). To calculate precipitation differences for elevations and HRUs, observed precipitation is adjusted by monthly correction factors (rain_adj, snow_adj). Daily maximum infiltration of snowmelt into the soil is defined for PRMS and GSFLOW (snowinfill_max). The surface runoff is computed using a nonlinear equation that takes into account antecedent soil moisture and rainfall (smidx_coef, smidx_exp). When the soil water reaches maximum soil water holding capacity, additional infiltration is routed to the subsurface and ground water reservoirs (soil2gw_max). Subsurface runoff is simulated as a nonlinear coefficient to route subsurface reservoir to streamflow (ssrcoef_sq). Within PRMS, the groundwater reservoir is conceptualized as a linear reservoir recession coefficient (gwflow_coef). PRMS also simulates the movement of water from a subsurface reservoir to a groundwater reservoir, computed as a routing function (ssr2gw_rate, ss2gw_exp). For calculating potential evapotranspiration, the Hamon method (Hamon, 1961) was used (hamon_coef). In the SSMU approach we included monthly corrections of maximum and minimum daily air temperatures for differentiation of energy balance calculations within HRUs.

An important distinction between the SSMU and BSPU approaches is the use of different ranges of parameters to predict the different hydrologic regimes in wet and dry seasons (e.g., Gan et al., 1997) of the SRB for the SSMU approach. The BSPU approach applied existing parameter sets developed for a larger basin to simulate the SRB streamflow, therefore the same parameter sets were used between wet and dry seasons. However, we found better fit of the SSMU model (GSFLOW) when different values were used for the evapo-transpiration parameter (hamon_coef), surface runoff exponent (smidx_exp), and groundwater routing coefficients (ssr2gw_rate, ssr2gw_exp, gwflow_coef) between the hydrologically active wet season compared to the baseflow driven dry season. The parameters for monthly corrections of precipitation and temperature did not improve model performance for the dry season and were not adjusted from a priori values for the SSMU approach.

\subsection{Uncertainty assessment}

For the assessment of uncertainty in posterior parameter ranges for the SSMU and BSPU approaches, we applied the Differential Evolution Adaptive Metropolis (DREAM) assessment (Vrugt et al., 2009). DREAM is a formal Bayesian approach that uses a Markov Chain Monte Carlo sampling algorithm to estimate the posterior probability density function of parameters, automatically tuning the scale and orientation of the $a$ priori distribution during evolution of the posterior parameter distributions. Posterior distributions of parameter values were developed from DREAM for three sub-basins representing the range of topographic and geologic conditions within the SRB. The posterior distributions from the 
Table 5

Range of parameter distributions for SSMU and BSPU modeling approaches produced with the DREAM uncertainty assessment.

\begin{tabular}{|c|c|c|c|c|c|}
\hline $\begin{array}{l}\text { Model } \\
\text { parameter }\end{array}$ & Parameter description & $\begin{array}{l}\text { A priori } \\
\text { parameter } \\
\text { range }\end{array}$ & $\begin{array}{l}\text { SSMU wet season posterior } \\
\text { parameter range }\end{array}$ & $\begin{array}{l}\text { SSMU dry season posterior } \\
\text { parameter range }\end{array}$ & $\begin{array}{l}\text { BSPU posterior } \\
\text { parameter range }\end{array}$ \\
\hline Rain_adj & Monthly rain adjustments by HRU & $0.7-2.0$ & $0.97-1.47$ & a & $0.7-1.3$ \\
\hline Snow_adj & Monthly snow adjustments by HRU & $0.7-2.0$ & $0.97-1.47$ & a & $0.7-1.3$ \\
\hline Tmax_lapse & Monthly maximum temperature lapse rates & $0-5$ & $3.2-4.2$ & a & a \\
\hline Tmin_lapse & Monthly minimum temperature lapse rates & $0-3.5$ & $3.0-3.1$ & a & a \\
\hline Hamon_coef & Hamon evapotranspiration coefficient & $0.004-0.009$ & $0.0082-0.009$ & $0.006-0.007$ & $0.004-0.008$ \\
\hline Smidx_coef & $\begin{array}{l}\text { Coefficient in surface runoff contributing } \\
\text { area computations }\end{array}$ & $0.0001-0.001$ & a & a & a \\
\hline Smidx_exp & $\begin{array}{l}\text { Exponent coefficient in surface runoff } \\
\text { contributing area computations }\end{array}$ & $0.1-0.9$ & $0.2-0.29$ & $0.2-0.78$ & $0.1-0.3$ \\
\hline Ssr2gw_rate & $\begin{array}{l}\text { Coefficient to route water from subsurface to } \\
\text { groundwater }\end{array}$ & 2.0 & $0.17-0.2$ & $0.14-0.25$ & $0.8-1.0$ \\
\hline Ssr2gw_exp & $\begin{array}{l}\text { Exponent coefficient to route water from } \\
\text { subsurface to groundwater }\end{array}$ & $0.2-2.0$ & $0.49-0.5$ & $1.4-1.94$ & $0.02-0.3$ \\
\hline Ssrmax_coef & Maximum gravity drainage to groundwater & $0.1-10.0$ & a & a & a \\
\hline Soil2gw_max & Maximum soil water to groundwater per day & $0.01-1.0$ & $0.09-0.1$ & a & $0.15-1.0$ \\
\hline Gwflow_coef & $\begin{array}{l}\text { Linear coefficient to route groundwater to } \\
\text { streams }\end{array}$ & $0.01-0.2$ & $0.011-0.015$ & $0.02-0.03$ & $0.01-0.05$ \\
\hline Snowinfil_max & Maximum snow infiltration per day & $0.1-10.0$ & $0.01-1.0$ & a & $2.0-10.0$ \\
\hline
\end{tabular}

${ }^{\text {a }}$ Posterior parameter range was no different than the apriori parameter range.

DREAM assessment were extrapolated to the remainder of the SRB based on similar physical characteristics to the three sub-basins. GCM and parameter uncertainties were addressed by cascading the range of model output from the posterior distribution of parameter sets through the eight GCMs. For further details on the DREAM uncertainty assessment and GSFLOW model validation, please see Surfleet and Tullos (2012).

\subsection{Evaluation of historical model fitness}

The fit of modeled streamflow for the three hydrologic modeling approaches was compared to measured daily and monthly streamflow (Table 6) for five USGS stream gauging stations for the historic period of 1960-2006 (Fig. 1). The stations on the South Santiam River at Waterloo, North Santiam River at Mehama, and Santiam River at Jefferson are below reservoirs. For consistency with previous modeling efforts (Hamlet et al., 2010; Chang and Jung, 2010), we made no correction to the measured streamflow to reflect reservoir modifications of the flow regime. We evaluated fit of historical streamflow above reservoirs at the North Santiam River below Boulder Creek and Santiam River at Cascadia, though no VIC output was directly available for the Santiam River at Cascadia location. We thus adjusted the VIC output for the South Santiam River at Waterloo by the unit area of South Santiam River at Cascadia. We also compared peak and low flow predictions to historic observations (Table 7). The Generalized Extreme Value distribution was used to estimate the 20,50 , and 100 year return peak daily streamflow and the 10-year 7-day low flow for the three model approaches and measured streamflow.

We also evaluated the fitness of the models to predict the Snow Water Equivalent (SWE) during the historic period. We were only able to perform this evaluation for the North Fork Santiam below Boulder Creek sub-basin because it was the only sub-basin entirely within the snow-dominated climate of the SRB (Fig. 1), and longterm snow measurements were not available for low elevation areas of the SRB.

Statistical fit of the monthly and daily time series to measured streamflow was evaluated by the Nash Sutcliffe efficiency (NS), Relative Efficiency (E rel), and percent bias (Pbias). The NS efficiency is a common measure of goodness-of-fit for hydrologic models that uses squared values (see the annotation of Table 6 for fitness measure equations), making them sensitive to high streamflow events. The E rel value modifies the NS as relative deviations, adjusting model fit based on size of event, thus better reflecting fit of the entire series and reducing the influence of the absolute differences during high flows. As a result, E rel values are more sensitive to systematic over- or under-prediction, in particular during low flow conditions (Krause et al., 2005), with higher values indicating higher model fit. Pbias describes the over- or under-estimation of simulated data relative to observed data, and tends to vary more during periods of low streamflow than high streamflow (Gupta et al., 1999). For Pbias, higher values indicate higher error or bias to observed data. Statistical fit to SWE in the North Santiam below Boulder Creek sub-basin was evaluated using the NS statistic.

\subsection{Comparison of projected change in future runoff}

For the LS approach, the range of estimates of peak flows and low flows from each of eight GCMs represent GCM uncertainty. No parameter uncertainty was available from the VIC modeling. For the BSPU and SSMU approaches, hydrologic response measures were calculated from $2.5,50$, and 97.5 percentile values of model output cascaded through eight GCMs to represent the uncertainty attributed to hydrologic model parameters. For the BSPU and SSMU approaches, we compared the GCM ensemble mean of the $2.5,50$, and 97.5 percentile values to the same percentiles from the range of historic predictions from the GCMs. The LS approach used bias corrected data and compared future predictions to a single historical value (Hamlet et al., 2010).

\section{Results}

\subsection{Fit of hydrologic model predictions to historic measurements}

\subsubsection{Monthly and daily streamflow}

Across all sites, all three modeling approaches provided acceptable (Moriasi et al., 2007) fit to measured monthly streamflow based on NS values greater than 0.7 and Pbias values $<10 \%$ with the exception of the two streamflow locations directly downstream of regulated streamflow from reservoirs (South Santiam at Waterloo and North Santiam at Mehama) (Table 6). Models of daily streamflow generated a greater range in the metrics of statistical fit than were generated for monthly streamflow estimates, 
Table 6

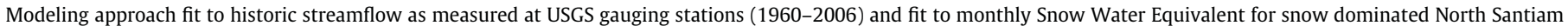

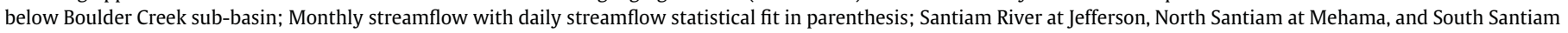
at Waterloo are below reservoirs with regulated flow.

\begin{tabular}{|c|c|c|c|c|c|c|c|c|c|}
\hline \multirow[t]{2}{*}{ USGS gauging station } & \multicolumn{3}{|l|}{ NS } & \multicolumn{3}{|c|}{ Pbias $(\%)^{\mathrm{c}}$} & \multicolumn{3}{|l|}{ E rel } \\
\hline & LS & BSPU & SSMU & LS & BSPU & SSMU & LS & BSPU & SSMU \\
\hline Santiam R. at Jefferson & $0.89(0.63)$ & $0.89(0.74)$ & $0.88(0.73)$ & 5.4 & 7.0 & 7.5 & $0.74(0.60)$ & $0.81(0.49)$ & $0.84(0.86)$ \\
\hline N Santiam at Mehama & $0.77(0.38)$ & $0.78(0.43)$ & $0.75(0.56)$ & 2.2 & 0.9 & 6.4 & $0.55(0.48)$ & $0.59(0.22)$ & $0.65(0.74)$ \\
\hline S Santiam at Waterloo & $0.85(0.50)$ & $0.82(0.66)$ & $0.55(0.52)$ & 1.2 & 5.5 & 0.9 & $0.57(0.35)$ & $0.51(0.48)$ & $0.39(0.73)$ \\
\hline N Santiam below Boulder Crk ${ }^{\mathrm{a}}$ & $0.61(0.51)$ & $0.80(0.62)$ & $0.70(0.71)$ & 7.7 & 12.0 & 12.6 & $0.38(0.51)$ & $0.56(0.67)$ & $0.72(0.79)$ \\
\hline South Santiam at Cascadia ${ }^{a}$ & $0.56^{\mathrm{b}}\left(0.87^{\mathrm{b}}\right)$ & $0.91(0.75)$ & $0.91(0.75)$ & 4.5 & 2.7 & 2.7 & $0.64(0.24)$ & $0.35(0.67)$ & $0.78(0.67)$ \\
\hline $\begin{array}{l}\text { Snow Water Equivalent - monthly } \\
\text { N Santiam below Boulder Crk }\end{array}$ & 0.95 & 0.86 & 0.96 & - & - & - & - & - & - \\
\hline
\end{tabular}

Nash-Sutcliffe efficiency (NS) $\left.=\left[\begin{array}{lllll}\Sigma\left(O_{i}\right. & \bar{O})^{2} & \Sigma\left(O_{i}\right. & S_{i}\end{array}\right)^{2}\right] / \Sigma\left(O_{i} \quad \bar{O}\right)^{2}$.

Percent bias (Pbias) $=\left[\begin{array}{ll}\Sigma S_{i} & \Sigma O_{i}\end{array}\right] / \Sigma O_{i} \times 100 \%$.

Relative Efficiency (Erel) $=1 \quad \Sigma\left(\frac{O_{i} S_{i}}{O_{i}}\right)^{2} / \Sigma\left(\frac{\left(O_{i} \overline{0}\right)}{\bar{O}}\right)^{2}$.

Here, $O$ is observed flow, $S$ is simulated flow, $n$ is a number of data, and $i$ indicates time.

a Streamflow not regulated by flood control dam; predominately snow dominated precipitation.

b VIC South Santiam at Cascadia is estimated by unit area from S. Santiam at Waterloo discharge.

c Percent bias is same for monthly and daily values.

Table 7

Comparisons of hydrologic model estimates for historic streamflow 10-year 7-day low flow.

\begin{tabular}{|c|c|c|c|c|}
\hline $\begin{array}{l}\text { Streamflow } \\
\text { source }\end{array}$ & $\begin{array}{l}\text { North Santiam below Boulder Creek } \\
\left(\mathrm{m}^{3} / \mathrm{s}\right)\end{array}$ & $\begin{array}{l}\text { North Santiam at Mehama } \\
\left(\mathrm{m}^{3} / \mathrm{s}\right)\end{array}$ & $\begin{array}{l}\text { South Santiam at Waterloo } \\
\left(\mathrm{m}^{3} / \mathrm{s}\right)\end{array}$ & $\begin{array}{l}\text { Santiam River at Jefferson } \\
\left(\mathrm{m}^{3} / \mathrm{s}\right)\end{array}$ \\
\hline Measured & 8.6 & 25 & 24.7 & 26.7 \\
\hline LS2 & 0.2 & 0.4 & 0.4 & 1.9 \\
\hline BSPU $^{a}$ & $0.1-19.9$ & $0.3-52.4$ & $0.03-5.5$ & $0.3-32.7$ \\
\hline SSMU1 & $7.8-9.5$ & $10.2-16.1$ & $3.5-9.1$ & $35.7-46.2$ \\
\hline
\end{tabular}

${ }^{\text {a }}$ Range of median values presented based on GCM and parameter uncertainty.

with NS values ranging from 0.38 to 0.87 (Table 6). There is no difference in Pbias values for daily or monthly streamflow because it is calculated by the proportion of sums of total streamflow. The Erel statistic results, representing fit of the entire time series but sensitive to low flow fitness of model output, are generally highest for SSMU than BSPU and LS for daily and monthly values except at the two locations directly below reservoirs.

For the two unregulated locations (S. Santiam River at Cascadia and N. Santiam River below Boulder (reek), the SSMU and BSPU approaches generally provide higher NS values, indicating better fit for high stream flows, than the LS approach. Comparing the approaches based on Pbias and Erel, SSMU had the highest Erel of the three approaches at North Santiam River below Boulder Creek and at South Santiam River at Cascadia, but also produced a high Pbias compared to the LS Approach for the same site. The LS approach generated streamflow values that had a lower underestimation bias (Pbias) but poorest fit across the time series (Erel) at N. Santiam below Boulder Creek. In contrast, the LS approach generated the highest Pbias but performed better than SSMU by the Erel fitness measure at the other unregulated site (S. Santiam River at Cascadia). Fitness measures for BPSU generally fell between values for LS and SSMU.

The evaluation of modeled streamflow fit for the three USGS gauging locations regulated by flood control dams requires cautious interpretation. The simulated streamflow for these locations did not consider flood control dams, so it is not realistic that hydrologic model output at locations in close proximity to dams would have close fit to measured streamflow. The flood control dams influence both high and low flow magnitudes, though the extent of these effects vary by season and year. For example, streamflow records, over the period of 1990-2010, at Foster dam indicate that the minimum ratio of outflow: inflow is 0 during the wet month of
January, indicating inflow is equal to outflow, but the ratio is 2.1 during the driest month of August, reflecting outflow that is twice that of the inflow (Tom Lowry, unpublished data).

These effects of flood regulation are likely to be less evident at the locations farthest downstream of the flood control dams for two primary reasons. First, lower basin sites drain a large area with un-regulated streamflows. For the SRB, approximately $40 \%$ of the basin area is located downstream of the reservoirs, representing $27 \%$ of the total precipitation that falls on the basin (PRISM Climate Group, 2012). Second, the number of diversions for irrigation, including municipal, irrigation, and commercial uses, increases with distance downstream in the SRB, mitigating, to some extent, the effect of dams on increasing summer baseflow. For example, while only 2 cfs ( 66 points of diversion) has been allocated above the site on the S. Fork of the Santiam at Cascadia, over $990 \mathrm{cfs}$ of water rights (1951 points of diversion) have been allocated in the Santiam River above the Jefferson site. Though these values reflect water rights rather than actual annual diversions and are likely not all consumptive uses, they illustrate how the intensity of diversions moving downstream into the agricultural areas of the basin, in combination with unregulated tributaries, likely mitigate some influences of higher baseflow releases from the reservoirs. Thus, while we acknowledge that the model results do not directly reflect the impacts of water management (flood control regulation and diversions), it is still constructive to compare model predictions in regulated and unregulated reaches to investigate systematic errors in the models.

In comparing the measured monthly and daily streamflow to model predictions at the location farthest downstream from flood control dams (Santiam River at Jefferson), we find that the SSMU approach generated predictions with the highest Erel values, though all three approaches had similar NS statistics of monthly 
and daily streamflow. Pbias at this far downstream site was high for the SSMU and BSPU approaches, with results trending towards overestimation (negative Pbias) for BSPU and SSMU and underestimation (positive Pbias) for the LS approach.

At the sites nearest to a regulating project (S. Santiam at Waterloo and N. Santiam at Mehama), the LS and BPSU approaches resulted in the highest NS statistics for monthly streamflow of the three modeling approaches. Interestingly, based on Pbias, the SSMU approach performed worst of the three models for the groundwater-based N. Santiam at Mehama while performing best in the mixed surface water-groundwater system draining to the S. Santiam at Waterloo location. An opposite pattern was seen with Erel values, with SSMU performing best of the three modeling approaches at the N. Santiam at Mehama site for both daily and monthly streamflow and worst at the S. Santiam at Waterloo location for the monthly, but not daily, streamflow. For both sites all approaches underestimated streamflow (positive Pbias), except the overestimation of streamflow (negative Pbias) with the LS approach for the N. Santiam at Mehama.

In summary, we see some general trends in model performance across the landscape and across model performance measures that are sensitive to different aspects of the hydrograph. These results suggest that, when comparing regulated streamflow observations to the unregulated model predictions, the SSMU approach generally performed best across all measures (except for Pbias at the N. Santiam below Boulder (reek). At the sites just downstream of the flood control projects LS outperformed SSMU for monthly statistics. At the site furthest downstream of the dams where the hydrologic impact of regulation is likely mediated to some extent, all approaches performed similarly with respect to the high flow fitness measures (NS) at the monthly resolution, though SSMU showed some greater fitness for daily resolution and across the entire series (E rel). However, SSMU and BSPU performed worse than LS with respect to low flow biases (Pbias).

\subsubsection{Snow Water Equivalent (SWE)}

SWE predictions by each of the modeling approach fit historical monthly SWE closely (Table 6). The NS were high for all three of the modeling approaches; NS values $\geqslant 0.82$. The BSPU approach had only slightly lower NS Values than the LS and SSMU approaches. Differences in posterior parameter values for the SSMU and BSPU approaches associated with precipitation and air temperature adjustments influenced the SWE predictions. The SWE statistical fit was based on only one snow measurement location and one sub-basin of the SRB, making it difficult to determine the efficacy of the model approaches at predicting SWE across the entire SRB. However, the hydrology of the sub-basin contributing to North Santiam below Boulder Creek streamflow is dominated by snow precipitation and predicting SWE in this basin gives us confidence in the energy calculations for snow processes for all of the model approaches.

\subsubsection{Extreme peak daily streamflow}

For the unregulated streamflow location (North Santiam below Boulder Creek), estimates of the historical extreme peak daily streamflow $(20,50$, and 100 year events) were very similar across the three modeling approaches (Fig. 2). At sites downstream of flood control projects (the North Santiam at Mehama, South Santiam at Waterloo, and Santiam River at Jefferson locations), the SSMU and BSPU peak flow estimates were consistently higher than peak flows calculated from observed streamflow. This overestimation of peak flows is expected since the influence of regulated streamflow from the flood control projects was not considered. However, the LS approach consistently underestimated the peak flow relative to measured streamflow for the three regulated locations. At the site nearest the dam (South Santiam at Waterloo), the

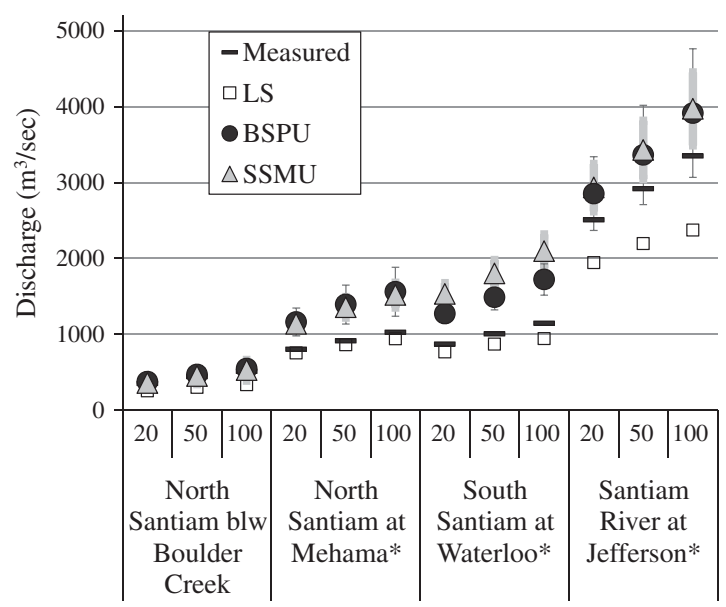

Peak Daily Flow Return Interval (20, 50, 100 yr) by River Location

Fig. 2. Comparisons of hydrologic modeling approach estimates for historic 20, 50, 100 year peak daily flow. LS estimate is mean value of eight GCM estimates from VIC. SSMU and BSPU estimates are the ensemble mean of median values and range of median estimates from cascading parameter uncertainty from GSFLOW and PRMS, respectively, through 8 GCMs. Thick grey line and thin black line error bars represent the 95 percentile uncertainty of median predictions from SSMU and BSPU approaches respectively. * - streamflow measured downstream of flood control dams.

LS model performed the best of all three approaches, as was seen with the daily and monthly model fit parameters. At the site with the largest drainage area (Santiam River at Jefferson), the LS model largely under predicted the peak flows, while the BPSU and SSMU approaches overestimated peak flows.

Results of the DREAM analysis (shown in Fig. 2 for BSPU and SSMU), reflects uncertainty in the estimates of peak flows as a function of both GCM and hydrologic model structure and parameterization. We note that the range of historical predictions was not available for comparison for the LS approach because the authors of the VIC model (Hamlet et al., 2010) identified only one historic value rather than the range of historic values from GCMs and because no uncertainty analysis was performed. For our own calculations with BSPU and SSMU, we found that the BSPU values had a wider range of the median peak flow predictions than the SSMU approach at all sites (Fig. 2), demonstrating greater uncertainty for BSPU estimates than for SSMU. The BSPU range of median predictions spanned approximately 15\% above and below the average historic peak flow predictions (approximately 30\% range) while the range of median SSMU predicted peak flows spanned approximately $10-15 \%$ above and below the average historic peak flow predictions (approximately 20-30\% range). The uncertainty increases moving downstream below the flood control dams, with the highest uncertainty range for both modeling approaches generated at the most downstream site (South Santiam at Jefferson).

\subsubsection{0-Year 7-day low flow}

The LS model underestimated historic low flow for all measured streamflow locations (Table 7). Both SSMU and BSPU estimates were also generally lower than the observed streamflow estimate for the three locations downstream of flood control dams, except for the site on the Santiam River at Jefferson where SSMU and some BSPU estimates over-predict the observed 10-year 7-day low flow, which is also reflected in the negative Pbias values (Table 6). This underestimation of flow is expected since reservoirs are generally releasing stored winter runoff for irrigation and domestic uses during the dry summer period. As noted previously, it is likely that the 
effects of reservoir releases is dampened in the downstream direction by additional runoff from tributaries and diversions for agricultural and municipal uses, hence the improvement in estimates of historical low flow at the farthest downstream site (Santiam River at Jefferson).

All three approaches underestimate the 10-year 7-day low flow of measured streamflow for North Santiam at Mehama and South Santiam at Waterloo, locations close to reservoirs. The low flow estimates from the LS approach are very low. The highest LS estimate of 10-year 7-day low flow, on the Santiam River at Jefferson, was only $7 \%$ of the 10 -year 7-day low flow calculated from measured streamflow ( $1.9 \mathrm{~m}^{3} / \mathrm{sec}$ compared to $26.7 \mathrm{~m}^{3} / \mathrm{sec}$; Table 7$)$. This systematic underestimation across the modeling approaches is likely due to the lack of representation of reservoir operations. For the unregulated streamflow location (North Santiam below Boulder Creek), the range of the median estimates of 10-year 7day low flow for SSMU and BSPU span the 10-year 7-day low flow calculated from observed streamflow, while the 10-year 7-day low flow estimate by the LS approach greatly underestimated the measured streamflow (Table 7).

In comparing BSPU to SSMU, we find that the range of BSPU $10-$ year 7-day low flow estimates was wider than SSMU at three of the sites than SSMU, similar to the wider range of peak flow estimates of the BSPU approach (Fig. 2). Further, the range of median estimates from BSPU often had values that were much lower than the 10-year 7-day low flow streamflow calculated from measured streamflow. We believe these differences in low flow magnitude and range are explained by the use of different parameter sets for the wet and dry seasons and a more sophisticated groundwater modeling by the SSMU approach. However, we cannot identify the relative importance to seasonal parameterization and groundwater model on model fit.

\subsection{Model parameters and structure}

The DREAM uncertainty assessment for the BSPU and SSMU modeling approaches produced different ranges of parameter values from the a priori parameter range for several parameters as well as important differences between the BSPU and SSMU models. These differences are likely due to the wet/dry season parameterization and to the interactions of a MODFLOW groundwater model with the SSMU approach. For example, the DREAM analysis converged on monthly rain and snow adjustments with a slightly higher but narrower range of values for the SSMU approach compared to BSPU (Table 5). Air temperature lapse rates were within a smaller range of values for the SSMU approach compared to BSPU. The Hamon evapotranspiration coefficient (hamon coef) was higher during the wet season for SSMU than the dry season, reflecting the need to increase evaporation rates in the wet season calculations. The exponent coefficient in surface runoff contributing area calculations, a coefficient of area in the non-linear surface runoff equation, varied between SSMU wet and dry seasons, illustrating parameter sensitivity to wet and dry conditions in the calculations. Differences exist in the parameters that control groundwater calculations (ssr2gw_rate, ssr2gw_exp, soil2gw_max, gwflow_coef) between the SSMU and BSPU approaches, emphasizing the importance of groundwater processes in the SRB. The greatest parameter differences between SSMU and BSPU were between the coefficients that route water to groundwater (ssr2gw_rate, ssr2gw_exp) and the coefficient that routes groundwater to streams (gwflow_coef). The exponent coefficient to route water from subsurface to groundwater was much lower for BSPU than SSMU (and the a priori parameter range). A lower exponent of groundwater routing indicates less groundwater recharge being predicted for BSPU compared to the SSMU approach. We also note that SSMU groundwater parameter ranges, when different from the a priori ranges, tended to have higher values for the wet season than the dry season in response to greater routing of groundwater to fit the model during wet season conditions.

\subsection{Differences in hydrologic model projections for climate change}

\subsubsection{Monthly streamflow}

The timing and magnitude of future runoff vary across the three modeling approaches (Fig. 3). Generally higher winter and lower summer runoff were predicted with LS and BSPU approaches than were predicted by the SSMU approach, particularly for the North Santiam locations (Fig. 3A and B) where groundwater has a stronger influence on the hydrology than at the South Santiam site (Fig. 3C).

In North Santiam below Boulder Creek, historically with snow dominated precipitation, the SSMU and BSPU approaches predict greater spring and summer runoff in the future than the LS approach (Fig. 3A). The North Santiam below Boulder Creek was the smallest basin evaluated. The differences between the future runoff predictions for the three approaches are most pronounced at this location. When modeling hydrology in a snow dominated basin, site-specific information on aspect and vegetation interception differences become more sensitive for model predictions as the basin size decreases. Further, the North Santiam below Boulder Creek historically has a higher spring and summer unit area runoff than the other study locations in SRB. The higher spring runoff can be attributed to spring snowmelt, however the higher summer runoff is attributed to long residence times and sustained groundwater discharges (Tague et al., 2008). The SSMU and BSPU approaches resulted in the best statistical fit to historical runoff for this location (Table 6), with the SSMU approach providing better fit to summer low flow (highest E rel value) of all approaches. Although it cannot be stated that historical fitness of a model corresponds to correct future predictions, we can state that the processes represented in this sub-basin were better captured by the SSMU and BSPU approaches.

\subsubsection{Extreme value peak daily flow}

The BSPU and SSMU approaches generally predicted a decrease in the 100-year event in all periods and scenarios, with small increases predicted by the SSMU models for the North Santiam at Mehama and South Santiam at Waterloo. In contrast, the LS approach predicts increases in the 20-, 50-, and 100-year peak flows (Fig. 4). Where increases in the 20- and 50-year events were predicted by the BSPU and SSMU approaches, they were no greater than $1-2 \%$ of the historical peak flow, while the LS approach predicted larger increases (5-40\% depending on location, time period, and emission scenario).

The uncertainty around predictions of BPSU peak flows (Fig. 4) demonstrates how the use of regional parameter sets lead to greater variability in the predictions of extreme peak flows. The BSPU approach predicted a range of peak daily flow of up to $25-35 \%$ above and below the average value (total range of $50-70 \%$ ) (Fig. 4). The SSMU approach predicted a deviation of peak daily flow values of approximately $10-25 \%$ above and below the average value (total range between $20 \%$ and $50 \%$ ). The LS approach had a slightly smaller range of peak flow predictions than SSMU, approximately 5-15\% above and below the average value. However, because no parameter uncertainty assessment was available for the LS approach, this range reflects only uncertainty due to use of different GCMs. In contrast, the uncertainty ranges for the BSPU and SSMU approaches characterize both parameter and GCM uncertainty. 
(A)


(C)
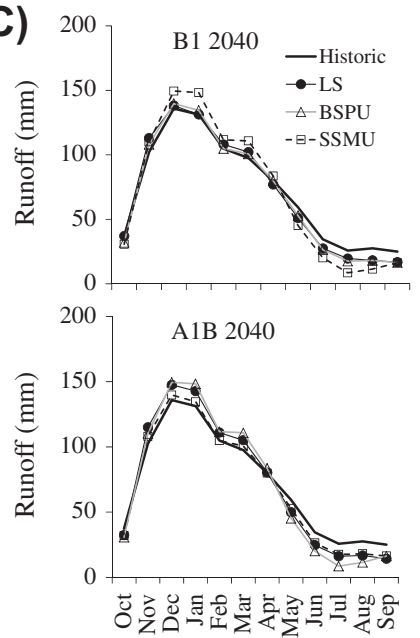
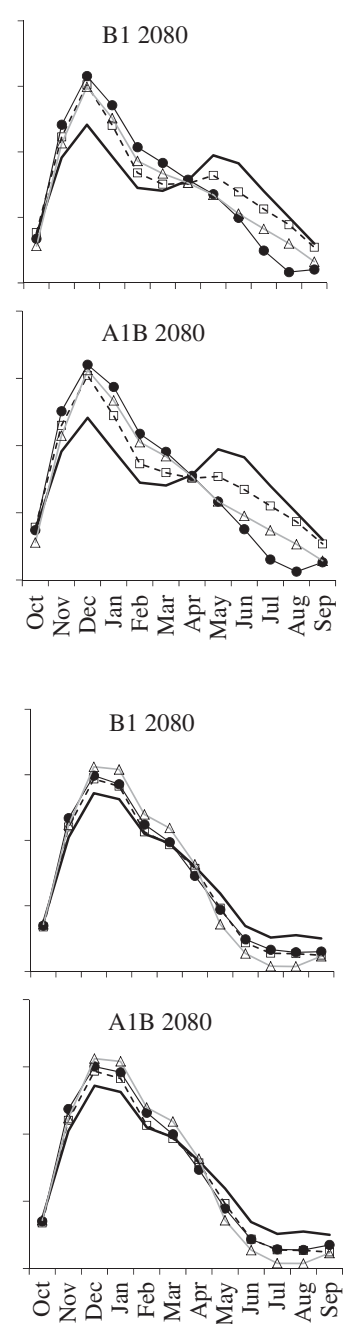

(B)
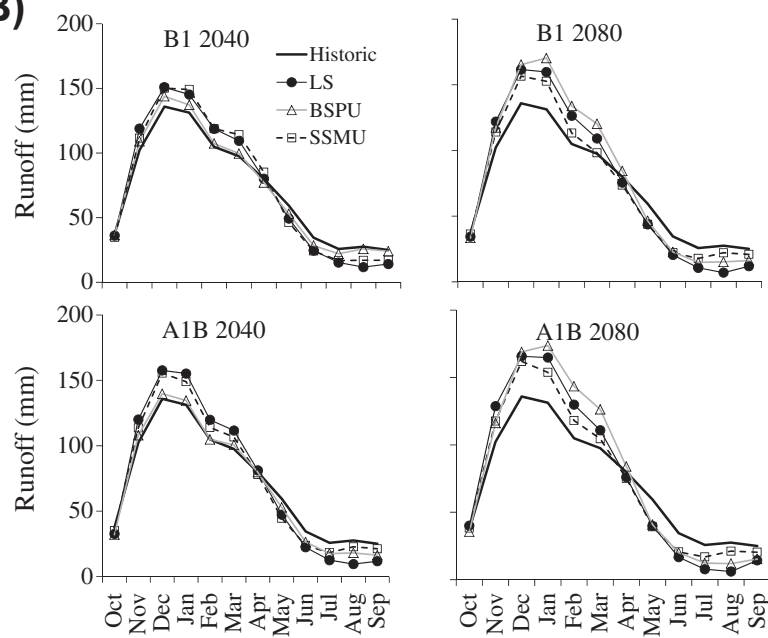

(D)
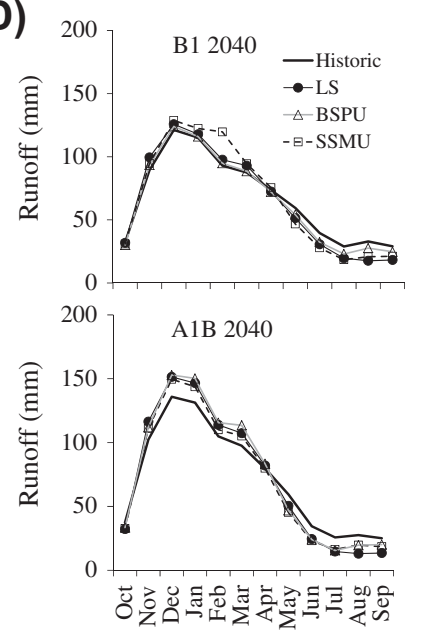
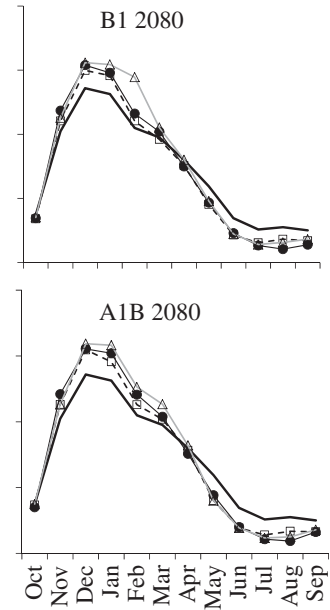

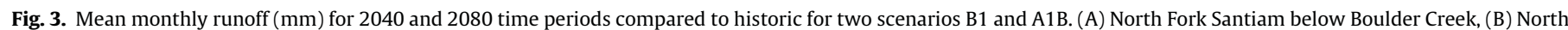
Santiam at Mehama, (C) South Santiam at Waterloo, and (D) Santiam at Jefferson.

\subsubsection{0-Year 7-day low flow}

The LS and BSPU approaches predicted decreases in the 10-year 7-day low flow for all future scenarios and time periods in the SRB (Fig. 5A-D). In contrast, the SSMU predicted no change in the 10year 7-day low flow in the future for North Santiam below Boulder Creek (Fig. 5A) and North Santiam at Mehama (Fig. 5B), both sites heavily influenced by groundwater. Further, the SSMU also predicted much smaller decreases in the 10-year 7-day low flow than LS or BSPU approaches for the South Santiam at Waterloo (Fig. 5C) and Santiam at Jefferson (Fig. 5D) locations. Both the high elevation and the lower alluvial areas of the SRB have significant groundwater interactions with streamflow. The high elevation areas, consisting of High Cascade geology, have long sub-surface water residence times producing continual discharge from sub-surface waters (e.g., spring fed streams) (Lee and Risley, 2002). The lower alluvial areas are locations of recharge to the valley aquifer in the wet season and discharges water for streamflow during the dry season. Likely as a result of the groundwater simulations, the SSMU approach predicted less change in low flow discharge and considerably lower uncertainty around the results than the BSPU and LS approaches (Fig. 5A-D). The BSPU approach had a high range of low flow predictions than SSMU, in some cases as much as four orders of magnitude (Fig. 5). The BSPU approach had its greater range of predictions, or highest uncertainty, in the North Santiam below Boulder Creek location (Fig. 5A). The North Santiam below Boulder
Creek has a substantial summer groundwater discharge and is not regulated by an upstream dam. The BSPU and LS parameter sets did not predict this summer groundwater influence as the SSMU approach, and generated a greater range of low flow results. All of the LS approach low flow values, including the historic value, are well below those calculated from measured USGS streamflow suggesting a high degree of uncertainty in the low flow estimates from the LS approach. However, without a parameter uncertainty assessment for the LS approach we do not know the amount of uncertainty associated with the LS approach predictions.

\subsubsection{Monthly Snow Water Equivalent (SWE)}

There was little relative difference in the average monthly SWE predicted by the three modeling approaches for the North Santiam River below Boulder Creek sub-basin for both 2040 and 2080 time periods for B1 and A1B scenarios (Fig. 6A). While the LS approach tended to underestimate SWE during the late summer months, relative to BSPU and SSMU approaches, historical fitness with the SWE for the North Santiam River below Boulder Creek was shown to be similar among the three approaches. This general similarity suggests that the above ground energy calculations for snow processes in the high elevation areas of the SRB were comparable among the model approaches. However, the change in SWE predictions for the entire SRB (as evaluated at the Santiam River at Jefferson) does vary among the approaches (Fig. 6B). The lower elevation 
(A)
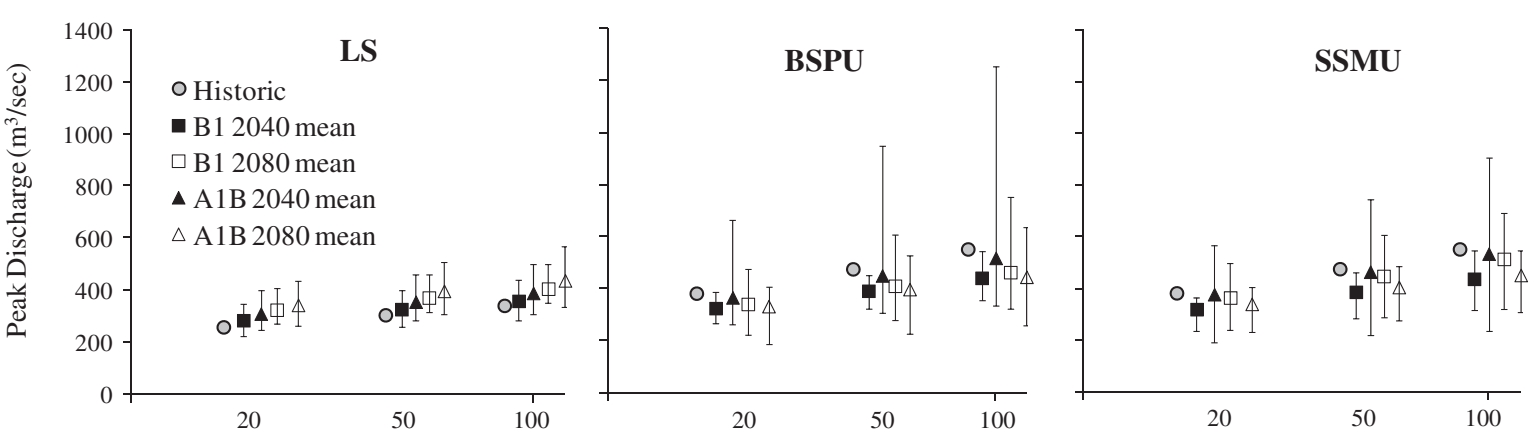

(B)


(C)


(D)
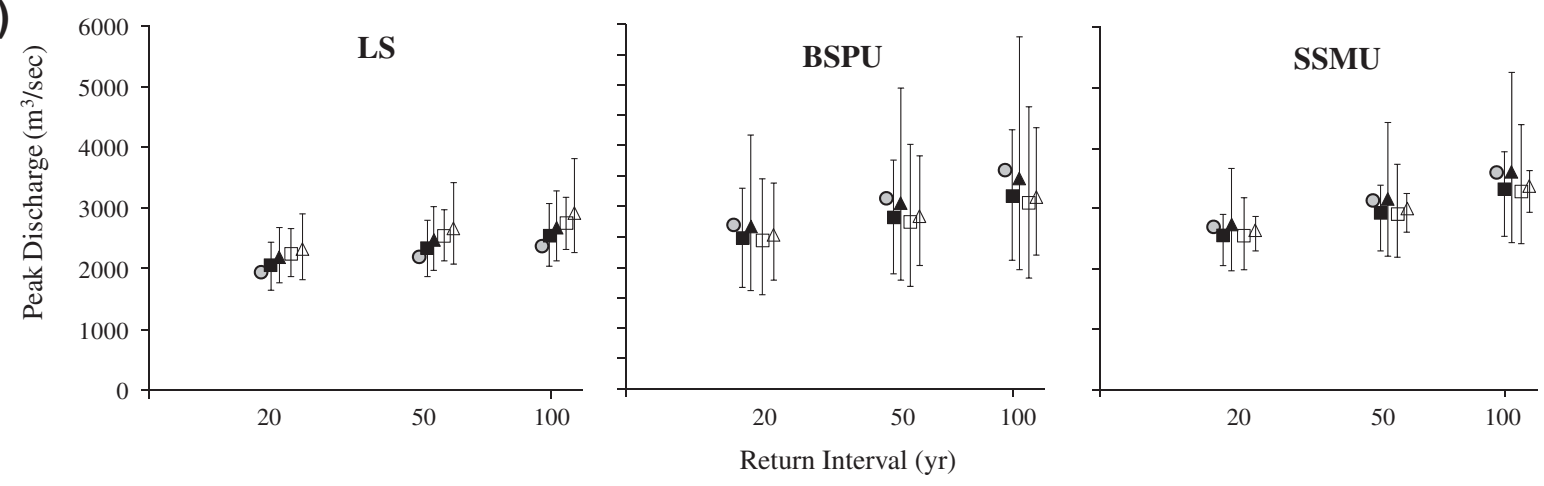

Fig. 4. Comparison of 20,50, and 100 year peak daily flow predicted by three modeling approaches for two climate change scenarios, B1 and A1B for 2040 and 2080 time

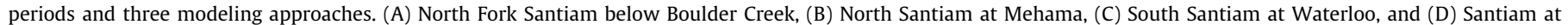
Jefferson. The markers indicate the percent change in median monthly values from historical observations while error bars indicate the percent change for 2.5 and 97.5 percentile predictions for SSMU and BSPU approaches or the range of results from only GCMs for the LS approach.

areas of the SRB have rain-dominated climate, with the middle elevations being a mix of rain and snow depending on the air temperature during the precipitation event. The LS approach predicted a slightly smaller decrease in SWE than SSMU or BSPU during the peak snow months (January through March) for the A1B scenario for both 2040 and 2080 time periods for the SRB. The SSMU and BSPU both predict less change in late summer SWE compared to the LS approach in the A1B scenario. During the B1 scenario the SSMU approach predicted approximately 15\% less decrease in SWE than LS approach during the late spring to early summer of the SRB, a period of declining snow water storage due to snow melt. During summer all model approaches show large decreases in summer SWE, however, there are only small amounts of snow in summer in the SRB, primarily in the highest elevations. 
(A)
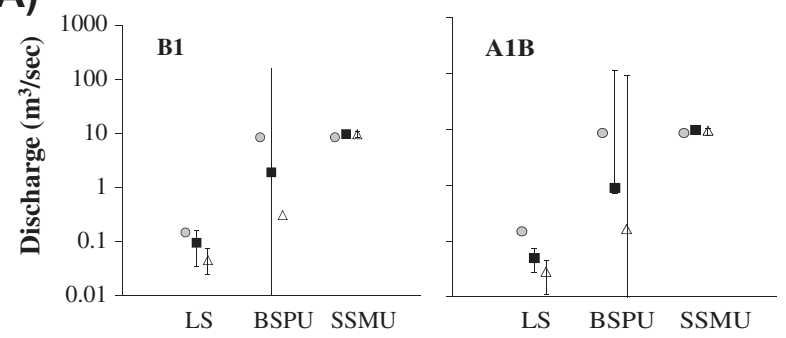

(C)
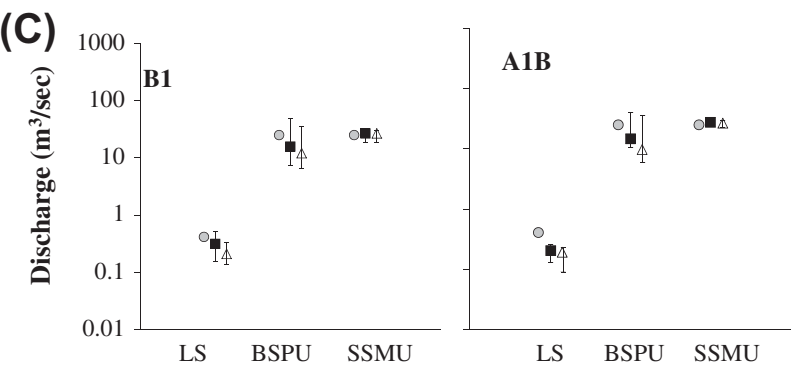
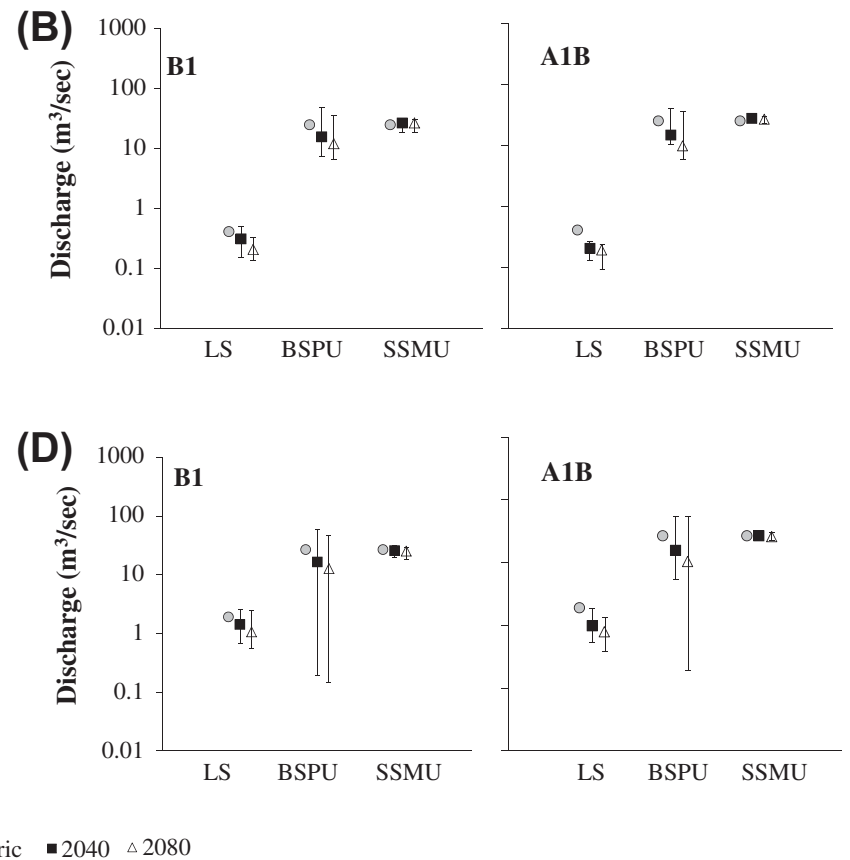

$\circ$ Historic $\quad 2040 \quad \Delta 2080$

Fig. 5. Comparison of 10-year 7-day low flow estimated from three modeling approaches for 2040 and 2080 time periods compared to historic for two climate scenarios B1

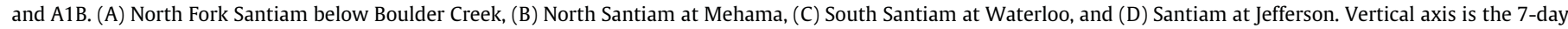

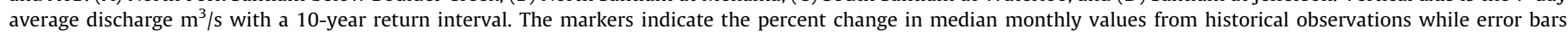
indicate the percent change for 2.5 and 97.5 percentile predictions for SSMU and BSPU approaches or the range of results from only GCMs for the LS approach.

\section{Discussion}

\subsection{Comparison of model approaches for historic and future hydrologic response}

Model performance varied across the sites and fitness measures with respect to historical streamflow. The SSMU approach generally provided the highest level of statistical fit across many of the hydrologic response metrics tested. The BSPU approach was second in level of fit to historic conditions, with notable inaccuracy in both SSMU and BSPU for the prediction of summer low flow (Pbias, Table 6) at two of the sites below dams and one of the unregulated sites. The SSMU and BSPU approaches had slightly better fit for historic daily streamflow than LS, particularly in the lower discharges of the summer season based on $\mathrm{E}$ rel values (Table 6).

When the modeling approaches were compared based on historical extreme events of peak flows (Fig. 2) and low flows (Table 7), the three approaches differ considerably. The LS approach underestimates the 20, 50 and 100 year peak flows and the 10-year 7-day low flows, as calculated from measured historical streamflow. The 10-year 7-day low flow prediction is particularly low, with predictions by the LS approach ranging from 0.2 to $1.9 \mathrm{~m}^{3} / \mathrm{s}$ across the sites compared to calculated values from measured streamflow of $8.6-26.7 \mathrm{~m}^{3} / \mathrm{s}$ (Table 7). The BSPU approach produced a wide range of low flows, spanning three to four orders of magnitude (Fig. 5). The overall better fit by the SSMU approach supports the conclusions from another model comparison (Hamlet et al., 2010), which found that models with finer scaling of local parameters offer better spatial representations of processes influenced by solar radiation (e.g., snowmelt, evapotranspiration).

Despite the similarity in historic SWE, the hydrologic responses associated with decreased SWE in the future differed among the three approaches; e.g., extreme peak flows, seasonal monthly runoff changes, or extreme low flows. The LS approach predicted future increases in the 20,50, and 100-year peak flows, while the
SSMU and BSPU approaches predicted either little change or decreases in these extreme peak flows. Similarly, the LS and BSPU approaches predicted large decreases in the 10-year 7-day low flow, while the SSMU predicted smaller decreases with low model uncertainty. All three modeling approaches predicted increases in runoff in winter months and decreases in summer months, but with differences in magnitude of change among the approaches. The most pronounced changes were at the smallest spatial scale evaluated, North Santiam below Boulder Creek, where groundwater influences and site specific topography in the parameterization of the models produced considerable differences in the predicted response (see Fig. 3A).

The differences in the future changes can be attributed not only to the scale of the modeling effort but also to the ability of the models to capture the local hydrologic processes. The parameter sets for each model approach were derived from different sources and levels of detail (see Table 2 and Section 2.2), resulting in variability in the how the hydrologic seasons and hydrogeology are represented in the models. For example, the greatest difference among the approaches was at the location on North Santiam below Boulder Creek, where BSPU and LS predict between 25-75\% decreases in streamflow for the summer months (June-August) yet SSMU predicts little streamflow decrease during this period. Given the relatively similar representation of land use and soils between the three models (Table 2), we interpret that these differences in low flow predictions are related to the presence of algorithms within the SSMU model that simulates groundwater interactions; This basin has substantial groundwater contributions that have been shown to mediate summer low flow changes to climate change in other areas of the Cascade Mountains (Chang and Jung, 2010; Tague et al., 2008). However, without detailed output on all of the hydrological processes for each of the models, we are unable to determine this relationship conclusively.

From the DREAM assessment, we found that the BSPU approach produced considerable uncertainty in model results. The BSPU approach used regional parameters within an uncertainty assessment. 
(A)


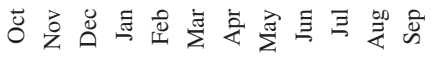

(B)


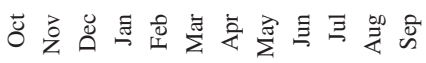

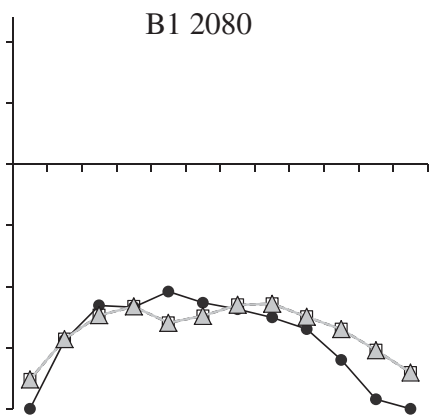

A1B 2080



B1 2080



A1B 2080



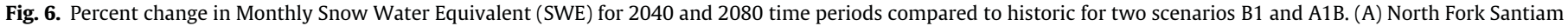

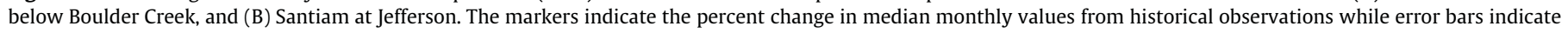
the percent change for 2.5 and 97.5 percentile predictions for SSMU and BSPU approaches or the range of results from only GCMs for the LS approach.

The parameter ranges were previously defined for the Willamette Valley and evaluated for prediction of the SRB hydrology. Further the BSPU parameters were developed for the entire streamflow record, not separated into two distinct seasons as was simulated for the SSMU approach. The higher uncertainty for the BSPU approach was expressed in both the 10-year 7-day low flow and extreme peak flow predictions (Figs. 5 and 6, Table 7). The change in 2.5,
50 , and 97.5 percentile values of BSPU outputs varied considerably among the different percentiles. When predicted change is consistent for all percentiles, greater confidence can be placed on conclusions regarding shifts in modeled hydrologic responses (Surfleet and Tullos, 2012). The differences in predicted change by percentiles in the BPSU responses alert the user to limitations in interpretations of the model results as evidenced by the high uncertainty in 
the BPSU estimates (Figs. 5 and 6). The high uncertainty with the BPSU approach likely resulted in part from the seasonal differences in hydrologic processes for the PNW. With different parameter sets (e.g. used different snow and precipitation adjustment rates, smaller range of air temperature lapse rates) to address the temporal differences in hydrology, as was used with SSMU, the BSPU approach would likely generate lower levels of uncertainty. Although not necessary in all hydrological settings, the separation of energy budget related parameters values between wet and dry seasons were useful for the SRB.

These results would not be evident without the analysis of parameter uncertainty, which greatly contribute to the interpretation of model results. For example, predictions of peak and low flows by the BPSU approach were found to have high uncertainty compared to SSMU predictions. The information that uncertainty was high in predictions provides both a contrast between approaches and the ability to better interpret predictions. VIC modeling in the LS approach focused on calibrated model parameters for the CRB east of the Cascade mountain divide (the majority of the CRB; Hamlet et al., 2010) without any analysis of parameter uncertainty across the landscape. This area of the CRB has a drier and colder winter than west of the Cascade mountain divide, with predominately snow precipitation. The SRB is located west of the Cascade mountain divide with generally warmer winters and mixed rain and snow precipitation. This parameter calibration approach may explain why the LS approach was not as accurate in the SRB. If a parameter uncertainty assessment was conducted for the LS approach, the result would likely have illustrated high uncertainty associated with its predictions. For example, this study found differences in accuracy and uncertainty of model predictions between the use of regionally developed parameters, e.g., BPSU approach, compared to parameters developed in a site specific approach, SSMU approach, even when both approaches were developed west of the Cascade divide.

\subsection{Model selection and management of climate change effects on water resources}

The approach to model development and interpretation can have important influences on the approach to water resources management (Beven, 2001). A number of key factors (e.g., parameterization for spatial heterogeneity in the landscape, presence of groundwater interactions, and spatial and temporal differences in climate) were identified in this study as potentially important to the selection of modeling approach.

Our results suggest that a site-specific approach to climate change modeling is more likely to represent the suite of processes that contribute to hydrology in areas where climate and hydrogeology are heterogeneous. In the SRB, the varied geologic setting created spatially-explicit ground and surface water interactions that were better captured by the SSMU approach than by LS and BSPU approaches. Consequently the SSMU approach generally provided a better fit to historical measurements, particularly at the smallest, unregulated sub-basin scale evaluated (North Santiam below Boulder Creek). As the size of the modeled basin increased, the benefits of the SSMU approach were less distinct and the BPSU and LS approaches provided similar levels of fitness to measured streamflow.

A LS approach may be appropriate in areas where the climate and hydrologic processes are relatively homogeneous. When a LS modeling approach is used in heterogeneous landscapes to inform water resources planning, parameterizing the model by different climate zone of the area would improve the reliability of model predictions. Detailed differences in mountain terrain, soil characteristics, and geology are not assessed in a LS approach; Processes that rely on accurate solar radiation flux (e.g., mountain snowmelt, sublimation, evaporation, or transpiration) can be inaccurately represented (Hamlet et al., 2010).

With each refinement of spatial scale for the modeling, the time and cost of the modeling increases, influencing the modeling approach selection. The resources required to develop SSMU models can be substantial, particularly when a large land area must be analyzed. For the analysis of the SRB presented here, the SSMU approach required a computer network with multiple nodes to perform the calculations and stochastic parameter selections required of the uncertainty assessment. This process took several months to complete.

When a site-specific or basin-scale modeling approach is justified but only a large-scale evaluation can be afforded, it is important that model uncertainty be evaluated. This can be approached in many different ways. Parameter uncertainty approaches are increasingly automated and incorporated in model use (e.g., Vrugt et al., 2009). At a minimum, sensitivity analysis of parameter values across hydrographic regions can provide some quantification of model uncertainty. Providing comparison of small scale site-specific modeling to predictions by the large-scale effort can give indications of short-comings in the large scale approach. For example, although differences were apparent between a coarse VIC and finer resolution DHSVM model, a (2010) comparison by Hamlet et al. found a clear advantage for using DHSVM at finer spatial resolutions for basins where spatial variation in solar radiation is an important driver of study outcomes (i.e. vegetation studies) or change in land use.

Ultimately, model selection should be based on consistency between the needed resolution of the water resources management issue and model structure, uncertainty, and resource demand. In a comparison of six different monthly water balance models in China (Jiang et al., 2007) and three semi-distributed models in South Korea (Bae et al., 2011), models were found to predict historic runoff equally well. However, large differences were found among the six models' results for perturbed climate change scenarios. The differences depended on climate scenarios, the season, and the hydrologic variable under investigation (Jiang et al., 2007). Other studies confirm that use of different hydrologic models for climate change studies have not provided consistent results based on climate change scenario and season (Boorman and Sefton, 1997; Panagoulia and Dimou, 1997).

If multiple sources of information (e.g., multiple modeling efforts) are available, all of the sources should be considered in water resources planning to increase confidence in the outcomes of management actions. For example, the SSMU approach predicted a decrease in the 100-year peak flow in the future for the North Santiam below Boulder Creek sub-basin. However, the LS approach predicted an increase in the 100-year peak flow for the same subbasin. A possible water resource decision could be to implement a policy to manage for the decreased 100 -year peak flow, but be prepared with an adaptive management strategy should the increase in the 100-year peak flow occur. In this case, the emphasis was placed on managing from site-specific results but implements an adaptive management strategy that considers all projected results. Again, we emphasize that uncertainty in the results of the modeling efforts should be used in the interpretation of the model results and consequently in the decision making process.

We note that recent studies (Merz et al., 2011; Rosero et al., 2010) have emphasized the potentially large biases resulting from the calibration of hydrologic model parameters to historic runoff due to the relationships between the climate (temperature, precipitation) and landscape (i.e. evapotranspiration, soil and groundwater storage) being nonstationary. Until new techniques, as well as those recently proposed (e.g. Singh et al., 2011), to address the temporal instability in climate and landscape relationships are developed and operationalized, assessment of climate change 
impacts will be limited by the ability of models to reliably represent hydrological processes that are changing with the climate.

\section{Conclusions}

This study demonstrated that differing hydrologic modeling approaches using the same downscaled GCM forcing data predicted different monthly, low flow, and peak flow changes due to climate change. The differences in the future changes can qualitatively be attributed not only to the scale of the modeling effort but also to the ability of the models to represent the suite of processes that contribute to hydrology in areas where climate and hydrogeology is heterogeneous and/or groundwater interactions contribute to hydrology. For the SRB, surface and groundwater interactions are influential in the water resource response to climate change. As expected, our results suggest that, in heterogeneous basins, a site-specific model generally provides greater accuracy over predictions from models developed for basin or large scale modeling efforts. However, a water resource manager might accept lower accuracy as an acceptable trade-off compared to the additional effort and resources needed for accuracy gained from a site-specific approach. As best practice in accepting the lower accuracy of large scale models, as well as in modeling efforts at any scale, our results emphasize the importance of: (a) performing parameter uncertainty analysis in providing confidence that a LS or BSPU modeling approach is predicting the macro changes or trends in, if not magnitude of, hydrologic response correctly, (b) to the extent possible, developing spatially and temporally variable parameterizations that reflect seasonal variability in the hydrograph and spatial variability in land use/land cover, soils, elevation, climate, etc. that occur at the sub-regional scale, and (c) algorithms reflecting groundwater interactions when predictions of low flow are an important management concern.

\section{Acknowledgements}

This material is based upon work supported by the National Science Foundation under Grant No. 0846360. Any opinions, findings, and conclusions or recommendations expressed in this material are those of the authors and do not necessarily reflect the views of the National Science Foundation. The research was also funded in part by the National Science Foundation through TeraGrid resources provided by Purdue University under grant number TGECS100006. We specifically acknowledge the assistance of Phil Cheeseman at Purdue University. Additional support for I.W. Jung was provided by the Institute for Sustainable Solutions at Portland State University. We received considerable assistance from R. Steven Regan and Rich Niswonger, of the United States Geological Survey, on the implementation and use of GSFLOW. Jasper Vrugt of University of California Irvine provided advice and computer programs for implementation of the DREAM analysis. Marketa M. Elsner, Research Scientist, University of Washington Climate Impacts Group provided parameter and modeling information on the VIC modeling of the Columbia River Basin.

\section{References}

Bae, D.H., Jung, I.W., Lettenmaier, D.P., 2011. Hydrologic uncertainties in climate change from IPCC AR4 GCM simulations of the Chungju Basin, Korea. J. Hydrol. 401, 90-105.

Bates, B., Kundzewicz, Z.W., Wu, S., Palutikof, J.P., 2008. Climate Change and Water. Technical Paper of the Intergovernmental Panel on Climate Change (IPCC), Geneva, pp. 1-210.

Beven, K., 2001. Rainfall-Runoff Modelling: The Primer. John Wiley and Sons Inc., West Sussex, England, 360p.

Boorman, D.B., Sefton, C.E., 1997. Recognizing the uncertainty in the quantification of the effects of climate change on hydrological response. Clim. Change 35, 415434.
Brekke, L.D., Kiang, J.E., Olsen, J.R., Pulwarty, R.S., Raff, D.A., Turnipseed, D.P, Webb, R.S., White, K.D., 2009. Climate Change and Water Resources Management: A Federal Perspective. USGS Circular 1331. <http://pubs.usgs.gov/circ/1331/>.

Chang, H., Jung, I.W., 2010. Spatial and temporal changes in runoff caused by climate change in a complex river basin in Oregon. J. Hydrol. 388, 186207.

Chang, H., Lawler, K., 2011. Impacts of climate variability and change on water temperature in an urbanizing Oregon basin. In: Peters, N., Krysanova, V., Lepisto, A., Prasad, R., Thomas, M., Wilby, R., Zandaryaa, S. (Eds.), Water Quality: Current Trends and Expected Climate Change Impacts, vol. 348. International Association of Hydrological Sciences Publication, pp. 123-128.

Clark, M.P., Slater, A.G., Rupp, D.E., Woods, R.A., Vrugt, J.A., Gupta, H.V., Wagener, T., Hay, L.E., 2008. Framework for understanding structural errors (FUSE): a modular framework to diagnose differences between hydrological models. Water Resour. Res. 44 (W00B02). http://dx.doi.org/10.1029/2007WR006735.

Collins, W., Bitz, C., Blackmon, M., Bonan, G., Bretherton, C., Carton, J., Chang, P., Doney, S., Hack, J., Henderson, T., Kiehl, J., Large, W., McKenna, D., Santer, B., Smith, R., 2006. The community climate system model version 3 (CCSM3). J. Clim. 19, 2122-2143.

Elsner, M.M., Cuo, L., Voisin, N., Deems, J.S., Hamlet, A.F., Vano, J.A., Mickelson, K.E.B., Lee, S.Y., Lettenmaier, D.P., 2010. Implications of 21st century climate change for the hydrology of Washington State. Clim. Change 102 (1-2), 225-260.

Franczyk, J., Chang, H., 2009. The effects of climate change and urbanization on the runoff of the Rock Creek in the Portland metropolitan area, Oregon, USA. Hydrol. Process. 23 (6), 805-815

Gan, T.Y., Dlamini, E., Biftu, G.F., 1997. Effects of model complexity and structure, data quality, and objective functions on hydrologic modeling. J. Hydrol. 192, 81-103.

Gordon, C., Cooper, C., Senior, C., Banks, H., Gregory, J., Johns, T., Mitchell, J., Wood, R., 2000. The simulation of SST, sea ice extents and ocean heat transports in a version of the Hadley Centre coupled model without flux adjustments. Clim. Dyn. 16, 147-168.

Gupta, H.V., Sorooshian, S., Yapo, P.O., 1999. Status of automatic calibration for hydrologic models: comparison with multilevel expert calibration. J. Hydrol. Eng. 4 (2), 135-143.

Hamlet, A.F., Lettenmaier, D.P., 1999. The effects of climate change on hydrology and water resources in the Columbia River basin. J. Am. Water Resour. Assoc. 35 (6), 1597-1623.

Hamlet, A.F., Carrasco, P., Deems, J., Elsner, M.M., Kamstra, T., Lee, C., Lee, S.Y., Mauger, G., Salathe, E.P., Tohver, I., Whitely Binder, L., 2010. Final Project Report for the Columbia Basin Climate Change Scenarios Project. <http:// www.hydro.washington.edu/2860/report/>.

Hamon, W.R., 1961. Estimating potential evapotranspiration, proceedings of the American Society of Civil Engineers. J. Hydraul. Div. 87 (HY3), 107-120.

Harbaugh, A.W., 2005. MODFLOW-2005, The U.S. Geological Survey Modular Ground-Water Model-the Ground-Water Flow Process: U.S. Geological Survey Techniques and Methods 6-A16, Variously Paginated.

Im, E.S., Jung, I.W., Chang, H., Bae, D.H., Kwon, W.T., 2010. Hydroclimatological response to dynamically downscaled climate change simulations for Korean basins. Clim. Change 100 (3), 485-508.

IPCC, 2007. Climate Change 2007: The Scientific Basis. IPCC Contribution of Working Group I to the Fourth Assessment Report of the Intergovernmental Panel on Climate Change. Cambridge University Press, Cambridge.

Jiang, T., Yougqin, D.C., Xu, C., Chen, X., Chen, X., Singh, V.P., 2007. Comparison of hydrologic impacts of climate change simulated by six hydrologic models in the Dongjiang Basin, South China. J. Hydrol. 336, 316-333.

Jung, I.W., Chang, H., 2011a. Assessment of future runoff trends under multiple climate change scenarios in the Willamette River Basin, Oregon, USA. Hydrol. Process. 25, 258-277.

Jung, I.W., Chang, H., 2011b. Climate change impacts on spatial patterns in drought risk in the Willamette River Basin, Oregon, USA. Theor. Appl. Climatol. 108, 355-371.

Jungclaus, J.H., Botzet, M., Haak, H., Keenlyside, N., Luo, J., Latif, M., Marotzke, J., Mikolajewicz, U., Roeckner, E., 2006. Ocean circulation and tropical variability in the coupled model ECHAM5/MPI-OM. J. Clim. 19, 3952-3972.

K-1 Model Developers, 2004. K-1 coupled model (MIROC) description. In: Hasumi, H., Emori, S. (Eds.), K-1 Technical Report 1: Center for Climate System Research. University of Tokyo, 34pp. <http://www.ccsr.u-tykyo.ac.jp/kyosei/hasumi/ MIROC/tech-repo.pdf $>$.

Krause, P., Boyle, D.P., Bäse, F., 2005. Comparison of different efficiency criteria for hydrologic model assessment. Adv. Geosci. 5, 89-97.

Laenen, A.L., Risley, J.C., 1997. Precipitation-Runoff and Streamflow-Routing Models for the Willamette River Basin, Oregon. U.S. Geological Survey Water-Resources Investigations Report 95-4284, 197p.

Leavesley, G.H., Lichty, R.W., Troutman, B.M., Saindon, L.G., 1983. PrecipitationRunoff Modeling System-User's Manual. U.S. Geological Survey WaterResources Investigations Report 83-4238, 207p.

Lee, K.K., Risley, J.C., 2002. Estimates of Ground-Water Recharge, Base Flow, and Stream Reach Gains and Losses in the Willamette River Basin, Oregon. US Dept Int., USGS Water-Resources Investigations Report 01-4215, 53p.

Liang, X., Lettenmaier, D.P., Wood, E.F., Burges, S.J., 1994. A simple hydrologically based model of land surface water and energy fluxes for general-circulation models. J. Geophys. Res. 99 (D7), 415-428.

Lohmann, D., Nolte-Holube, R., Raschke, E., 1996. A large scale horizontal routing model to be coupled to land surface parameterization schemes. Tellus 48 (5), 708-721. 
Mantua, N., Tohver, I., Hamlet, A., 2010. Climate change impacts on streamflow extremes and summertime stream temperature and their possible consequences for freshwater salmon habitat in Washington State. Clim. Change 102, 187-223.

Markstrom, S.L., Niswonger, R.G., Regan, R.S., Prudic, D.E., Barlow, P.M., 2008 GSFLOW-Coupled Ground-Water and Surface-Water FLOW Model Based on the Integration of the Precipitation-Runoff Modeling System (PRMS) and the Modular Ground-Water Flow Model (MODFLOW-2005). US Geological Survey Techniques and Methods 6, p. 240.

Marti, O., Bracommot, P., Bellier, J., Benshila, R., Bony, S., Brockmann, P., Cadulle, P., Caubel, A., Denvil, S., Dufresne, J., Fairhead, L., Filiberti, M., Hourdin, F., Krinner, G., Levy, C., Musat, I., Talandier, C., 2005. The New IPSL Climate System Model: IPSL-CM4. Institut Poerre Simon Laplace des Sciences del'Environnement Global. <http://dods.ipsl.jussieu.fr/omamce/IPSLCM4/>.

Maurer, E.P., Duffy, P.B., 2005. Uncertainty in projections of streamflow changes due to climate change in California. Geophys. Res. Lett. 32 (L03704). http:// dx.doi.org/10.1029/2004GL021462.

Maurer, E., 2007. Uncertainty in hydrologic impacts of climate change in the Sierra Nevada, California, under two emissions scenarios. Clim. Change 82, 309-325.

Merz, R., Parajka, J., Bloschl, G., 2011. Time stability of catchment mode parameters: implications for climate impact analyses. Water Resour. Res. 47 $1-17$.

Min, S.K., Legutke, S., Hense, A., Kwon, W.T., 2005. Internal variability in a 1000-year control simulation with the coupled climate model ECHO-G. Part I. Near-surface temperature, precipitation and sea level pressure. Tellus 57A, 605-621.

Moriasi, D.N., Arnold, J.G., Van Liew, M.W., Bingner, R.L., Harmel, R.D., Veith, T.L., 2007. Model evaluation guidelines for systematic quantification of accuracy in watershed simulations. Trans. ASABE 50, 885-900.

Mote, P.W., Parson, E.A., Hamlet, A.F., Ideker, K.N., Keeton, W.S., Lettenmaier, D.P., Mantua, N.J., Miles, E.L., Peterson, D.W., Peterson, D.L., Slaughter, R., Snover, A.K., 2003. Preparing for climate change: the water, salmon, and forests of the Pacific Northwest. Clim. Change 61, 45-88.

Najafi, M.R., Moradkhani, H., Jung, I.W., 2011. Assessing the uncertainties of hydrologic model selection in climate change impact studies. Hydrol. Process. 25, 2814-2826.

Nijssen, B.N., Lettenmaier, D.P., Liang, X., Wetzel, S.W., Wood, E.F., 1997. Streamflow simulation for continental-scale river basins. Water Resour. Res. 33 (4), 711 724.

NRCS, 1986. General Soil Map, State of Oregon: Portland, Oregon, Natural Resource Conservation Service, Scale 1:1,000,000.

NRCS, 2007. Hydrologic Soil Groups. US Dept. of Agriculture National Engineering Handbook, Part 630 Hydrology, 14p (Chapter 7). <http://directives.sc.egov. usda.gov/OpenNonWebContent.aspx?content=17757.wba>.

NRCS, 2011. United States Dept. of Agriculture Natural Resources Conservation Service Snow Telemetry (SNOTEL) Sites. <http://www.wcc.nrcs.usda.gov/ snotel/Oregon/oregon.html>.

Panagoulia, D., Dimou, G., 1997. Linking space-time scale in hydrological modelling with respect to global climate change. Part 2. Hydrological response for alternative climates. J. Hydrol. 194, 38-63.
Praskievicz, S., Chang, H., 2011. Impacts of climate change and urban development on water resources in the Tualatin River Basin, Oregon. Annals of the Association of American Geographers 101 (2), 249-271.

Prism Climate Group, 2012. PRISM Map of Annual Precipitation of the United States. $<$ http://prism.oregonstate.edu/>.

Rosero, E., Yang, Z.L., Wagener, T., Gulden, L., Yatheendradas, S., Niu, G.Y., 2010 Qunatifying parameter sensitivity, interaction, and transferability in hydrologically enhanced versions of the Noah land surface model over transition zones during the warm season. J. Geophys. Res. 115, 1-21.

Singh, R., Wagener, R., van Werkhoven, K., Mann, M., Crane, R., 2011. A tradingspace-for-time approach to probabilistic continuous streamflow predictions in a changing climate. Hydrol. Earth Syst. Sci. 8, 6385-6417.

Singh, V.P., 1995. Computer Models of Watershed Hydrology. Water Resource Publications, Highlands Ranch, CO.

Surfleet, C.G., Tullos, D., 2012. Uncertainty in hydrologic response due to climate change; Santiam River, Oregon. Hydrol. Process. http://dx.doi.org/10.1002/ hyp.9485.

Tague, C., Grant, G., Farrell, M., Choate, J., Jefferson, A., 2008. Deep groundwater mediates streamflow response to climate warming in the Oregon Cascades. Clim. Change 86, 189-210.

Terray, L., Valcke, S., Piacentini, A., 1998. Oasis 2.2 Ocean Atmosphere Sea Ice Soil User's Guide and Reference Manual, Technical Report TR/CMGC/98-05. CERFACS, Toulouse, France.

US Geological Survey (USGS) Seamless, 2009. National Map Seamless Server. $<$ http://seamless.usgs.gov/index.php>.

Vrugt, J.A., terBraak, C.J.F., Diks, C.G.H., Higdon, D., Robinson, B.A., Hyman, J.M., 2009. Accelerating Markov chain Monte Carlo simulation by differential evolution with self-adaptive randomized subspace sampling. Int. J. Nonlinear Sci. Numer. Simul. 10 (3), 273-290.

Washington, W., Weatherly, J., Meehl, G., Semtner, A., Bettge, T., Craig, A., Strand, W., Arblaster, J., Wayland, V., James, R., Zhang, Y., 2000. Parallel climate model (PCM) control and transient simulations. Clim. Dyn. 16, 755-774.

Wilby, R.L., Troni, J., Biot, Y., Tedd, L., Hewitson, B.C., Smith, D.M., Sutton, R.T., 2009. A review of climate risk information for adaptation and development planning. Int. J. Climatol. 29 (9), 1193-1215.

Wood, A.W., Leung, L.R., Sridhar, V., Lettenmaier, D.P., 2004. Hydrologic implications of dynamical and statistical approaches to downscaling climate model outputs. Clim. Change 62, 189-216.

Xu, C.Y., Widén, E., Halldin, S., 2005. Modelling hydrological consequences of climate change - progress and challenges. Adv. Atmos. Sci. 22 (6), 789-797.

\section{Further reading}

Wigmosta, M.S., Vail, L., Lettenmaier, D.P., 1994. A distributed hydrologyvegetation model for complex terrain. Water Resour. Res. 30, 1665-1679. 